\title{
THE STUDY OF CHANGES IN THE STRUCTURAL AND MECHANICAL PROPERTIES OF TURKEY FILLET DURING STORAGE
}

\author{
Svetlana Shapoval \\ Department of Engineering and Technical Disciplines \\ Kyiv National University of Trade and Economics \\ 19 Kioto str., Kyiv, Ukraine, 02156 \\ Shapovalknteu@gmail.com
}

\begin{abstract}
The method and equipment for the study of changes of structural-mechanical properties of turkey fillet at storage were offered. The improved express-method of the study allows determine the relaxation effort and time at axial deformation and the firmness limit of meat fibers using penetration.

The selection of registering equipment and sensors for the study of structural-mechanical properties of turkey fillet was grounded. The methods of compensation of axial displacement of sensors at the study of penetration and relaxation were described. The principal scheme, appearance and example of work of setting were given.

The changes of firmness and relaxation effort of cooled turkey fillet at different storage terms were characterized.

It was established, that organoleptically perceptible changes of structural-mechanical properties of turkey fillet take place after 46 hours of storage. In first turn, relaxation is decelerated, the firmness limit is lowered that together with less firmness limit of fibers allows recommend it for formation of natural culinary goods of the given form, for example, rolls.

The offered equipment and methodology of getting results of axial relaxation and penetration allows make conclusions about the essence of changes of rheological properties of turkey fillet and also recommend the studied samples for one or another type of culinary processing.
\end{abstract}

Keywords: penetration, structural-mechanical properties, turkey fillet.

\section{Introduction}

The structural-mechanical properties of meat samples are traditionally determined organoleptically. After pressing on the meat sample, the time of previous form restoration is determined visually [1].

But such method has its shortcomings: from subjective human perception of time and necessary experience to unknown structure of sample under the pressed surface.

In technique it is used to study the firm properties of real bodies by deformation graph that reflects the graphic dependency between relative deformation and mechanical tension, received experimentally $[2,3]$.

The structural-mechanical properties of the raw material determine the quality of culinary products of poultry, but it is difficult to detect them organoleptically. The mechanical properties of meat depend on forage, age, sex of poultry and essentially differ in different sets $[4,5]$. That is why the elaboration of universal methods and equipment for the study of structural-mechanical properties of the meat raw material under condition of mini-productions is an urgent problem.

The main aim was to elaborate the methods of the study of structural-mechanical properties of turkey fillet for recommendation of optimal type of culinary processing.

The task of research was to improve the methods of the study of poultry meat structure that allow fix insignificant changes of rheological properties that are difficult to detect organoleptically.

\section{Materials and Methods}

The series of experiments was carried out at the laboratory of Kyiv National university of Trade and Economics (KEUTE), Ukraine.

For fixing effort in the process of relaxation and penetration the series of dynamometers ITM Load-5.3/3s of Ukrainian production with measuring limit 2,6..6 N was used. Dynamome- 
ters, used at relaxation and penetration are equipped with triaxial stabilization of indenter to diminish its deviation from vertical line [6].

The digital measuring bloc UMCD, made by "ITM" LTD (Kharkiv, Ukraine) was used for fixing indications of dynamometers [7]. The electric bloc was produced in metal body. On the upper surface of the body are situated four inputs of DB-15 type, intended for connection of external devices (analogous and digital sensors). On the right side surface of the body is the input of USB-B type for connection with computer. The exchange of data between computer and electric bloc and also the power supply of electric bloc and sensor is realized through connecting flex USB A-B.

The registration of sensors indicators takes place in the program "Multimedia laboratory MIG-1.3" (Kyiv, Ukraine) that is a frame of program "Teaching laboratory ITM" (Kharkiv, Ukraine). The frame was created to facilitate the study of physical properties of the raw material and food products.

The photo of elaborated setting is given on the Fig. 1.

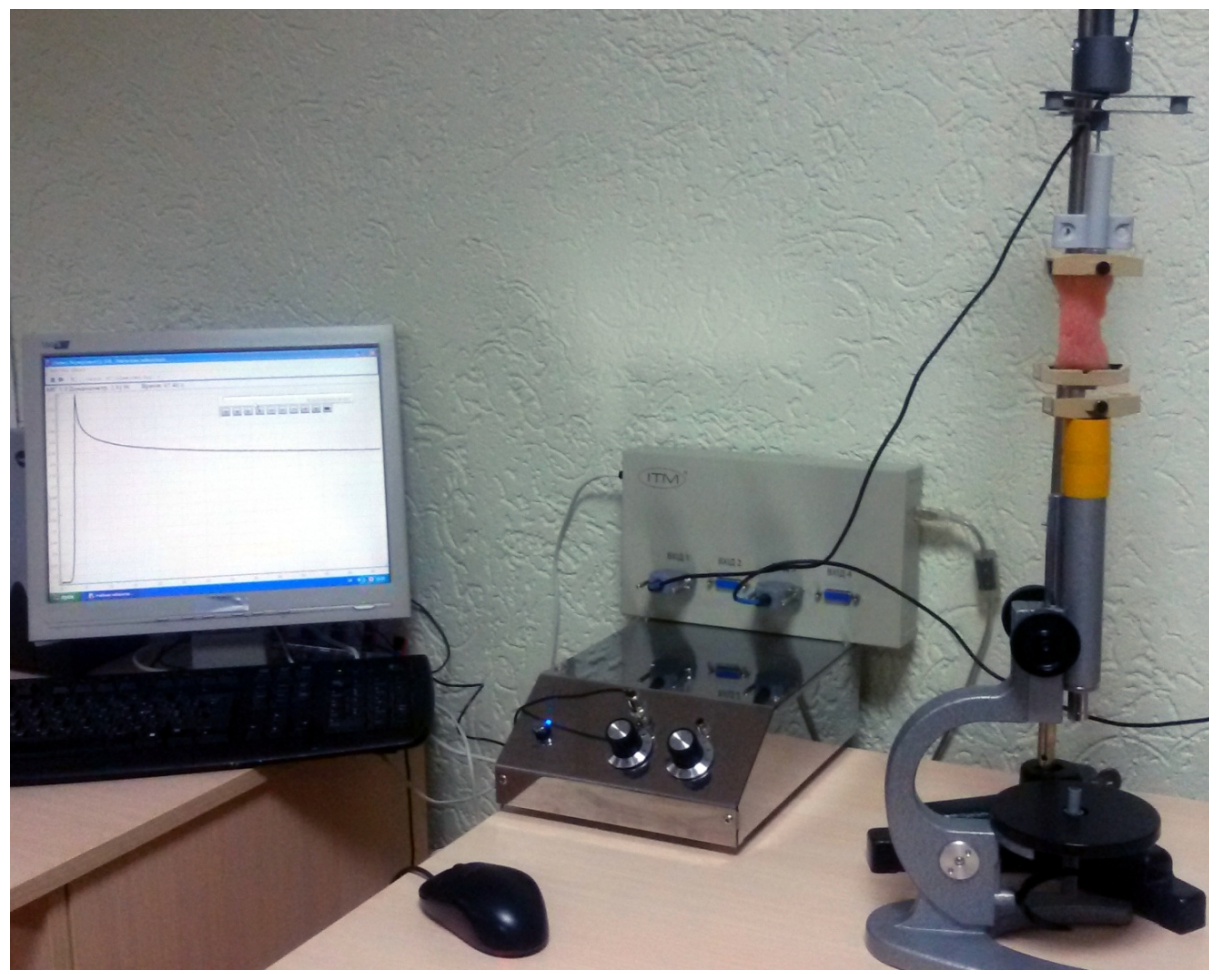

Fig. 1. The setting for study of dynamics of changes of relaxation effort of turkey fillet at extension deformation

The software was used for dependency modeling: office package ApacheOpenOffice 4.1.0 (USA), Delaware, especially the table processor Calc, made by ApacheSoftwareFoundation (USA), the program for formation and analysis of graphs AdvancedGrapher 2.2 by AlentumSoftware (Israel).

The studies were carried out with threefold (penetration with twelvefold) repeat, the processing of results was realized with reliability 0,95 . The measurement was carried out with exactness, optimal for each problem.

At the study of relaxation the data volume was up to three thousand points that is why the influence of casual errors is minimal. Because of irreversible changes each sample underwent axial deformation only once. Under such conditions, the large number of experiments needs big unreasonable expenditures. That is why it was decided to limit the study to three experiments for each fillet of certain storage term.

At penetration the essential casual error appears because of unevenness of product structure, that is why it was decided to increase the multiplicity of measurements to the maximal number 
on one sample under condition of non-hitting of the same place by indenter twice. Depending on sample, there were received 16-12 reliable results. At the next stage the most and least values of indenter resistance force were rejected to receive 12 results for each sample.

For testing the methods there were used the samples of cooled turkey fillet, produced by "Turkey" LTD (Sumy, Ukraine) in vacuum packing with storage term 7 days at temperature $0 \ldots+6{ }^{\circ} \mathrm{C}$.

The possibility to realize the first experiment appeared in 6 hours of storage after the packing time, indicated by producer. The second and third experiments were carried out in 22 and 46 hours after production. The unevenness of interval is explained by the laboratory working hours.

The results of the study of the structure of samples, stored during 70 and 94 hours essentially differed from the data, given in article that is explained by the processes of partial autolysis of tissues.

Because of partial deformation of structure, the relaxation effort at axial extension deformation was carried out only once for one sample, that is why the study for each storage time was carried out on three samples. The samples were extended along the fibers by $15-20 \%$ of initial length.

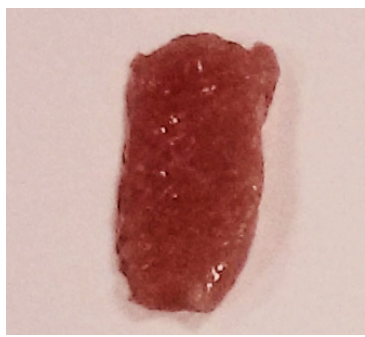

$a$

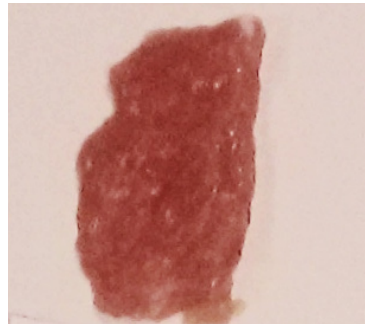

$d$

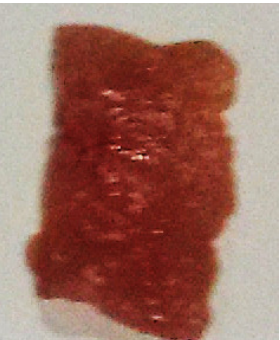

$g$

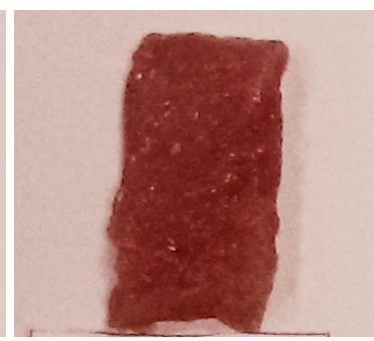

$b$

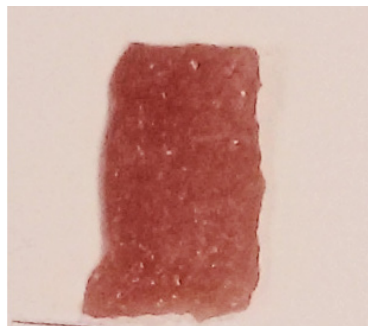

$e$

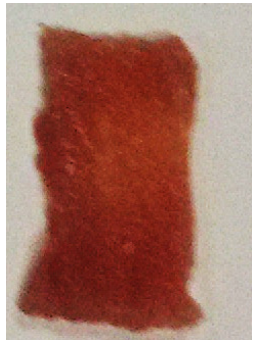

$h$

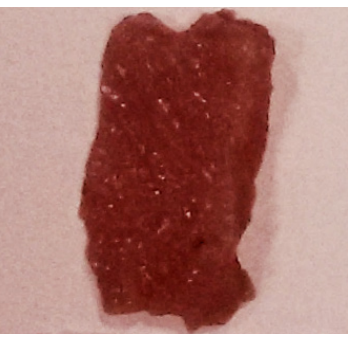

c

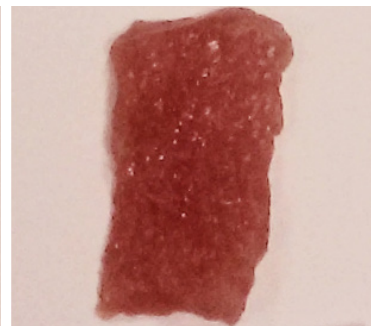

f

Fig. 2. The turkey samples before axial extension deformation: $a-\mathrm{c}-$ samples 1 (6 hours of storage); $d-\mathrm{f}-$ ssamples 2 (22 hours of storage); $g-i$ - samples 3 (46 hours of storage)

The mean arithmetical value of relaxation speed was taken for further processing of the results of relaxation effort.

The penetration was carried out $6 \ldots 14$ time on one sample, each time in new place at angle $85 . .95^{\circ}$ to muscular fibers with permanent speed of indenter immersion in product. The indenter of cylindrical form with diameter $1,5 \mathrm{~mm}$ was used. 
All experiments were carried out at maximal temperature of storage $+7 \pm 0,5^{\circ} \mathrm{C}$.

As far as at formation of natural culinary products the crucial role is played by deformation of extension but not compression, there was elaborated the equipment, which allows detect the relaxation parameters at axial extension deformation.

For studying the relaxation of turkey fillet the setting of original construction MIG 1.3, elaborated at laboratory of KNUTE together with "ITM" LTD (city Kharkiv, Ukraine), was used. The scheme of setting is presented on the Fig. 3.

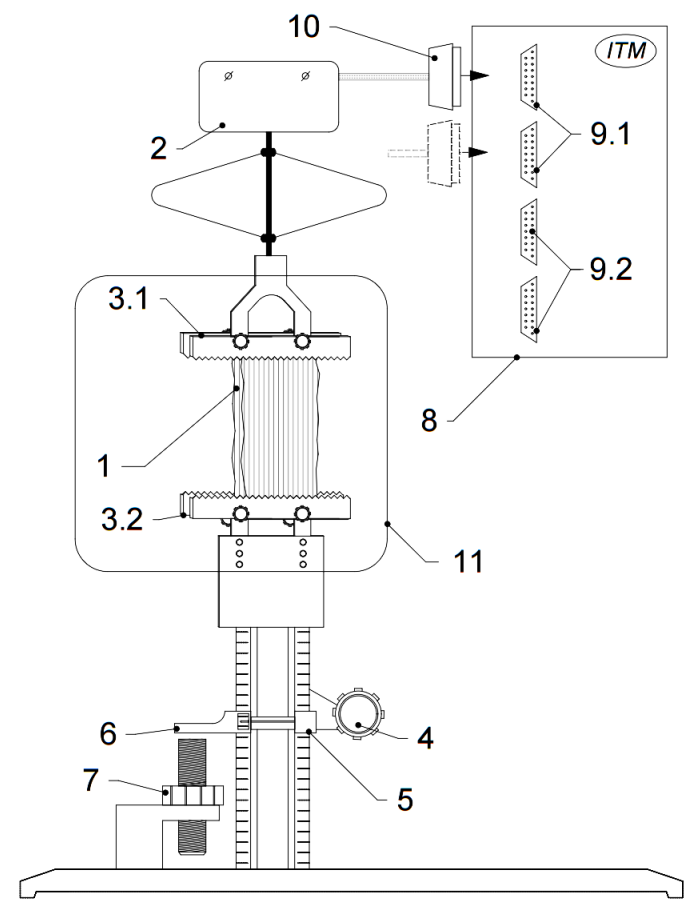

Fig. 3. The scheme of "Rheology" module of setting MIG 1.3:

1 - studied sample, 2 - digital dynamometer, 3.1 - upper stationary fixer,

3.2 - low movable fixer, 4 - handle for lifting and lowering of low fixer, 5 - stand with rule,

6 - height limiter, 7 - screw of height limiter, 8 - measuring cell, 9.1 - digital inputs,

9.2 - analogous inputs, 10 - socket of measuring module, 11 - measuring cell

The studied sample (1) was clamped by the upper (3.1) fixer and hung down freely during $5-10 \mathrm{~s}$ for smoothing the form. After that it was connected to the low (3.2) fixer and the length of the part of sample between fixers was detected.

The 1/5 size of sample length was inset by the screw of height limiter (7). The platform together with low fixer was evenly lowered by turning the handle (4) along the stand (5), till the height limiter (6) is stopped by screw (7).

The experiment was carried out during 60-120 s. The fixing of indications was stopped, if during $10 \mathrm{~s}$ the sample resistance effort did not change by $1 \%$ from the current value. For visible comparison of the results the data volumes were limited to 60 seconds.

The sample was in extended state during aforesaid time (during experiment). During the whole time of relaxation the digital dynamometer fixed the values of sample resistance force with measuring period $0,005 \mathrm{~s}$. The received data were kept in memory of MIG 1.3 and exported to the table processor for further processing.

The scheme of measuring cell of sample with marking the vector of forces, acting in studied sample, is presented on the Fig. 4.

The experiment is carried out under compulsory condition of absence of vibration of working surfaces and floor of laboratory. 
The lowering of the low part of construction, as opposite to the upper one, prevents the transmission of vibration from handle turning on dynamometer and also diminishes the vibration of movable part of dynamometer itself.

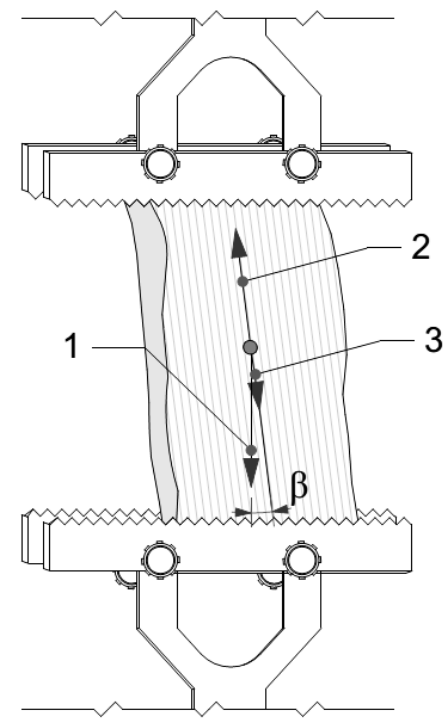

Fig. 4. The measuring cell of "Rheology module" of setting MIG 1.3.

The scheme of interaction of forces at extension of meat samples along fibers: $1-\operatorname{load}\left(\overrightarrow{\mathrm{F}}_{\mathrm{sp}}\right)$; 2 - relaxation effort $\left(\overrightarrow{\mathrm{F}}_{\text {rel }}\right) ; 3$ - weight of sample $\left(\overrightarrow{\mathrm{P}}_{\text {smpl }}\right)$

Mechanical ways of extinguishing vibrations and digital damping were not used because of inevitable disfiguration of data.

Before the beginning of experiment the sample is clamped in measuring cell, in given direction of fibers, but as far as muscular tissue has uneven structure, it is not possible to inset sample at precisely determined angle. The three-point system of dynamometer stabilization allows compensate deviation $(\beta)$ between load vector $\left(\overrightarrow{\mathrm{F}}_{\mathrm{sp}}\right)$ and resistance force vector $\left(\overrightarrow{\mathrm{F}}_{\text {rel }}\right)$ up to $5^{\circ}$ at load up to $6 \mathrm{~N}$.

After extension of sample by certain value (15-20\% of initial length), it is immovable. The processes of changes and deformation of structure that take place in it lead to the decrease of resistance force $\left(\overrightarrow{\mathrm{F}}_{\text {rel }}\right)$. The sample is also influenced by its weight $\left(\overrightarrow{\mathrm{P}}_{\text {smpl }}\right)-$ on the Fig. 4, for facilitation of perception, the point of sample weight application is presented in the center of body masses, although the point of sample weight application must be in the center of upper fixer (Fig. 1, (3.1)). But as far as the sample weight $\left(\overrightarrow{\mathrm{P}}_{\text {smpl }}\right)$ is a stable value and is essentially less that resistance and load force, the sample weight can be neglected.

The resultant of forces after extension of sample is equal to null. At diminishing of resistance force (relaxation effort, $\left.\overrightarrow{\mathrm{F}}_{\mathrm{rel}}\right)$, the load is diminished too $\left(\overrightarrow{\mathrm{F}}_{\mathrm{sp}}\right)$, the load is fixed by digital dynamometer in real time.

The scheme of setting for the study of limit of meat surface firmness by penetration method is given on the Fig. 5.

As far as meat structure is uneven and at hitting the connective tissue by indenter, the value of resistance force can differ in times from the value of resistance force of muscular tissue, the penetration of samples was carried out 8-10 times by both indenters. That is $16-20$ data points were received.

The inset of thermometers within indenters is conditioned by temperature influence on surface phenomena, especially adhesion between material of indenter and meat. If in the process of measuring the temperature changes more than by $2{ }^{\circ} \mathrm{C}$, such experiment is considered as unreliable one. 


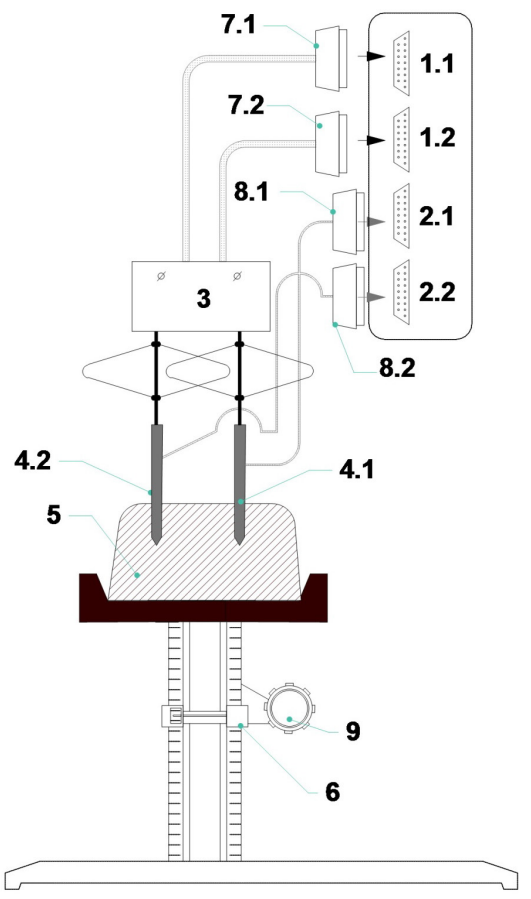

Fig. 5. The scheme of module "Penetration" of setting "MIG C 1.3": 1.1, 1.2 - analogous inputs, 2.1, 2.2 - digital inputs, 3 - dynamometer, 4.1, 4.2 - indenters with thermometers,

5 - studied sample, 6 - stand with rule, 7.1, 7.2, 8.1, 8.2 sockets DB-15, 8 - measuring cell, 9 - handle for lifting and lowering of low fixer, 10 - socket of measuring module, 11 - measuring cell

\section{1. Experimenta Iprocedures}

After deformation of sample, the software of measuring bloc formed the diagram of muscular tissue relaxation. The example of data of one sensor of elaborated setting at deformation of turkey fillet sample № 1 is presented on the Fig. 6.

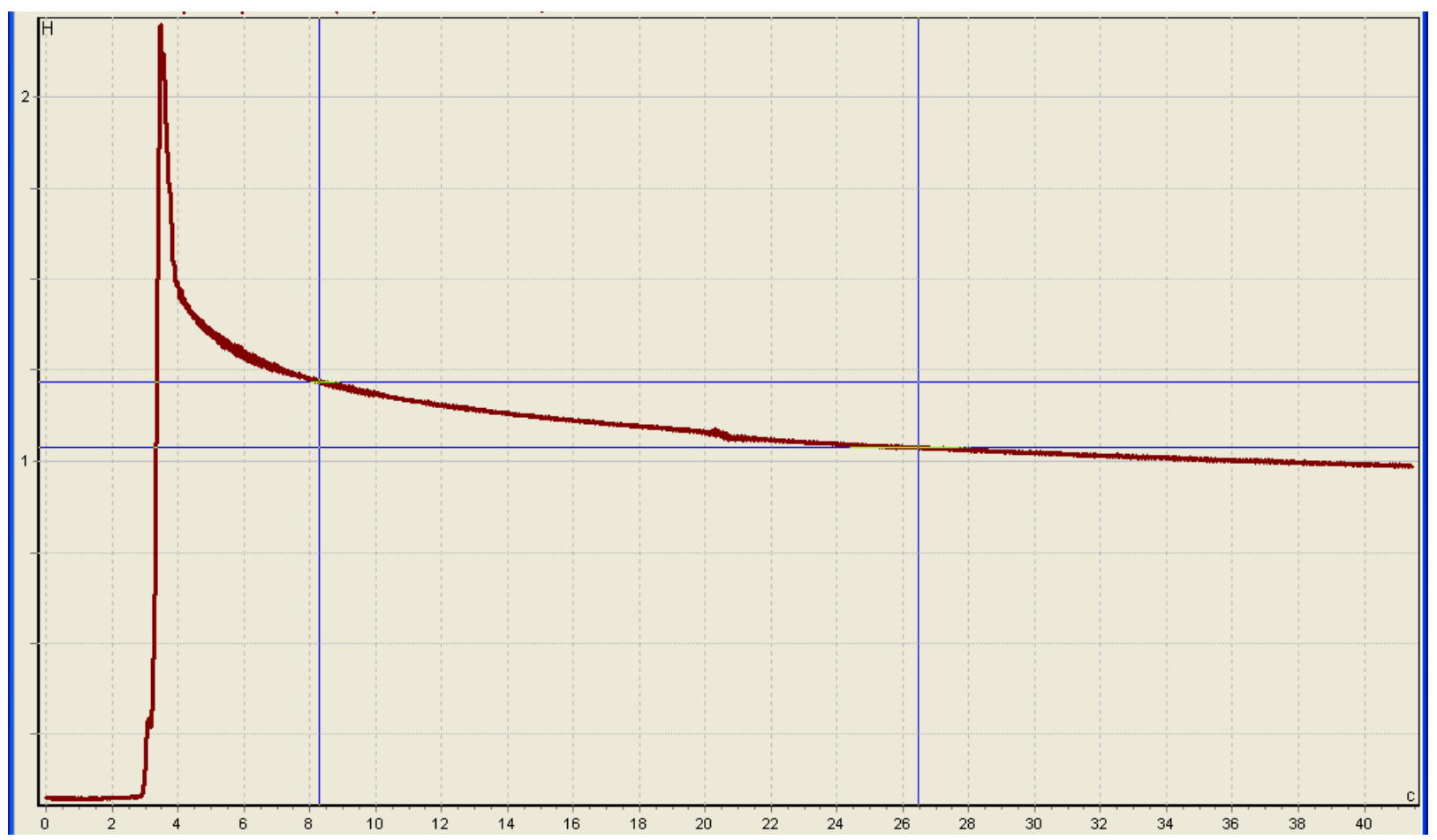

Fig. 6. The window of program "Multimedia laboratory MIG 1.3". The graph of deformation of turkey fillet sample № 1 at extension along the fibers 
In further the data were exported to the table processor for processing. The initial graph of deformation is hold for journal or protocol of research.

The example of computation of firmness limit of muscular fibers by penetration method is given on the Fig. 7

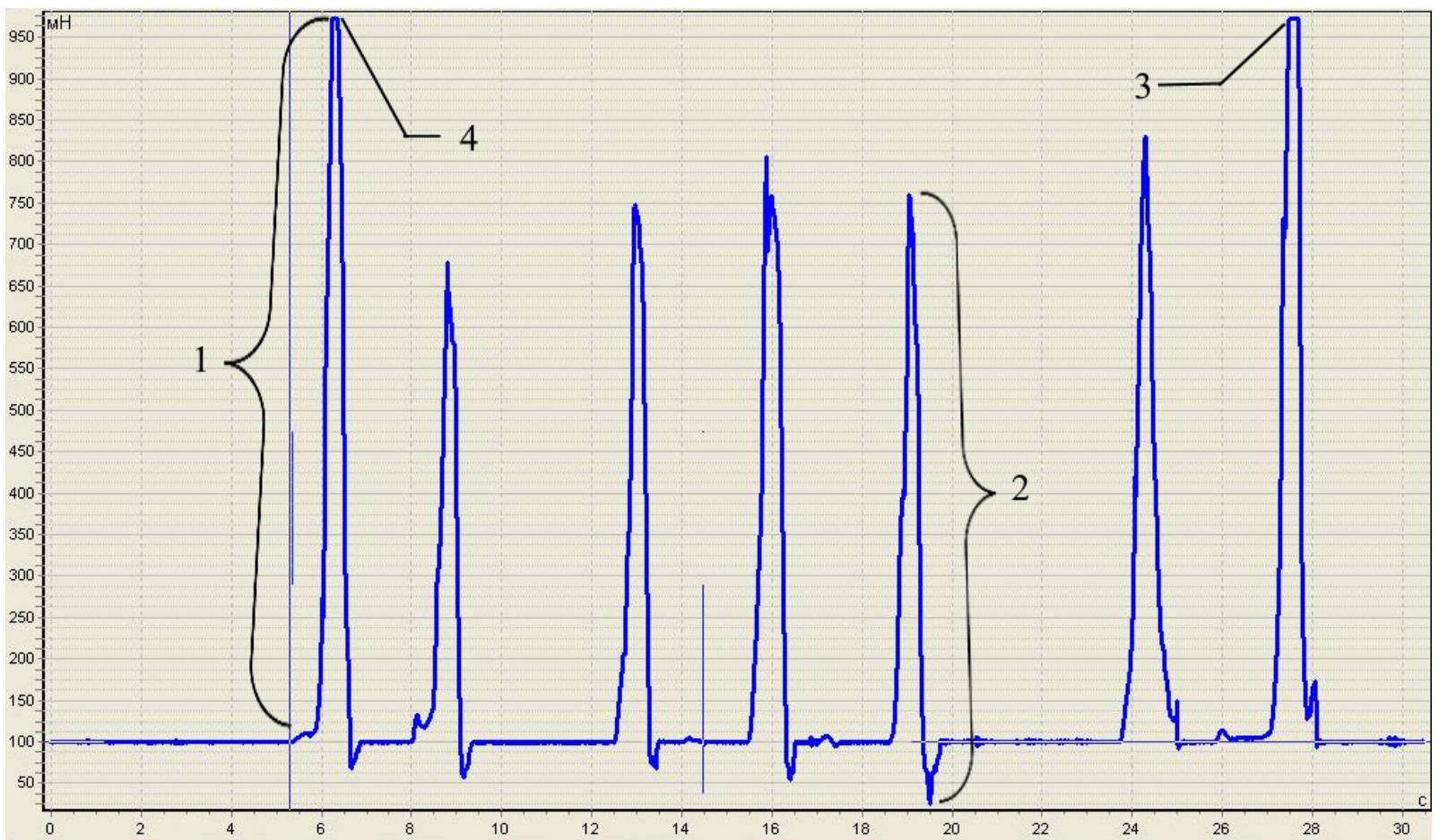

Fig. 7. The window of program "Multimedia laboratory MIG 1.3". The computation of firmness limit of turkey fillet sample 1 by penetration method at angle $85-95^{\circ}$ to the fibers: 1 - sector of resistance force growing; 2 - sector of resistance force diminishing, intensified by adhesion of product, 3 - penetrating effort at unsuccessful experiment (indications of dynamometer are beyond the measuring scale of device), 4 - penetrating effort

The structure firmness is usually assessed by the special parameter - value that characterizes the degree of indenter penetration within the studied sample of material under the effect of permanent load. This parameter characterizes the structure firmness of material at little deformation speeds. For assessing the structure of such complicated systems as meat it is not expedient to use it [8] that is why it was offered to use the cylindrical indenter and fix the resistance force of product, dipping indenter at the permanent speed up to the permanent depth [9]. At dipping the resistance force increases fast (Fig. 7, sector 1), but after rupture of the sample surface (in our case, the muscular fibers in surface layer), the muscular tissues resistance abruptly decreases (Fig. 7, sector 2). The graph of change of resistance force in time creates peak (Fig. 7, mark 4), which measuring helps to calculate the firmness limit of product surface.

\section{Results}

After analysis of relaxation diagrams we can get equations and angles of inclination of tangents (Table 1) to the graph of change of resistance effort in time. The most difference of inclination angles of tangents was observed at $4 \mathrm{~s}$ of relaxation that is why these very data are given for analysis of curves.

The difference between inclination angles of tangents of the samples 1 and 2 are within statistical error. The difference between the angle of tangent of the sample 3 and inclination angles of tangents of other samples is reliable. It indicates the essentially slower restoration of turkey fillet structure after application of deforming force during $4 \mathrm{~s}$. This difference is imperceptible organo- 
leptically, but after 46 hours of storage, autolytic processes essentially influence the firm properties of turkey fillet [1].

In technological aspect, fillet, stored more than 46 hours, is expedient to be used for product of special form, rolls or twisted cakes.

The relative penetrating strain $\left(\Theta_{\Pi}\right)$ and firmness limit of muscular tissue surface $\left(\Theta_{\mathrm{og}}\right)$ were calculated by the method [10]. The results of penetration of turkey fillet are given in the Table 2.

Table 1

The analysis of tangents to the graph of relaxation of turkey fillet samples at $4 \mathrm{~s}$ of relaxation

\begin{tabular}{cccc}
\hline $\begin{array}{c}\text { Sample № } \\
\text { (storage term) }\end{array}$ & Derivative of relaxation equation & Equation of tangent & $\begin{array}{c}\text { Inclination } \\
\text { angle of tangent, }{ }^{0}\end{array}$ \\
\hline 1 (6 hours) & $\mathrm{y}^{\prime}(\mathrm{x})=-0.63 \mathrm{x}^{-1}$ & $-0.158 \mathrm{x}+7.205$ & -8.970 \\
$2(22$ hours $)$ & $\mathrm{y}^{\prime}(\mathrm{x})=-0.67 \mathrm{x}^{-1}$ & $-0.147 \mathrm{x}+6.996$ & -8.388 \\
$3(46$ hours $)$ & $\mathrm{y}^{\prime}(\mathrm{x})=8.28 \mathrm{x}^{-0.0921}-0.0921 \mathrm{x}^{-1}$ & $-0.167 \mathrm{x}+7.308$ & -9.477
\end{tabular}

Table 2

The results of penetration of turkey fillet samples of different storage term

\begin{tabular}{|c|c|c|c|c|c|}
\hline \multirow{2}{*}{ Sample № } & \multicolumn{3}{|c|}{ Penetrating effort, $\mathrm{mN}$} & \multirow{2}{*}{$\begin{array}{l}\text { Relative penetrating } \\
\text { load }\left(\Theta_{n}\right), P a\end{array}$} & \multirow{2}{*}{$\begin{array}{l}\text { Limit of surface } \\
\text { firmness }\left(\Theta_{\mathrm{og}}\right), \mathrm{Pa}\end{array}$} \\
\hline & $\mathbf{P}_{\max }$ & $\mathbf{P}_{\min }$ & $\overline{\mathbf{P}}$ & & \\
\hline 1 & 955 & 534 & 734 & 3262.22 & $3849.42 \pm 137.12$ \\
\hline 2 & 948 & 432 & 692 & 3146.64 & $3713.07 \pm 87.18$ \\
\hline 3 & 946 & 352 & 627 & 2786.67 & $3288.27 \pm 116.05$ \\
\hline
\end{tabular}

Note: $P_{\max }-$ maximal resistance effort, $P_{\min }-$ minimal resistance effort, $\bar{P}-$ mean arithmetical resistance effort

Having analyzed the Table 2 , it can be noted, that any essential changes of fibers firmness were not observed during 22 hours of storage. But after 46 of storage of turkey fillet, the firmness limit of surface changed by $15 \%$ at pricking by cylindrical intender across fibers.

\section{Conclusions}

The setting MIG 1.3 of original construction was used at the study of structural-mechanical changes of turkey fillet properties. It was established, that during 22 of storage the significant changes of structural-mechanical properties took place, thus, for example, the relaxation time increased by $18,4 \%$ and the firmness limit of surface decreased by $0,9 \%$. During the following 24 hours of turkey fillet storage, the relaxation energy decreased by $11 \%$ (by $29 \%$ after the beginning of research) and the firmness limit also decreased that together with less firmness limit of fibers (by $15 \%$ ), allowed recommend it for formation of natural culinary product of given form, for example, rolls or twisted cakes.

The elaborated method was tested at warehouse of learning-producing institution KNUTE. It also can be used at mini-productions, culinary departments or laboratories of wholesale institutions for evaluation of raw material quality.

In further it is planned to improve the setting by introduction of managed movable platform for samples to automate experiments and eliminate the human factor influence on the results of experiment.

The authors form the data base of rheological properties of turkey meat that allows approximately establish the age of turkey, fat, storage term by determination of rheological properties of sample, and recommend the optimal type of culinary processing of studied set of poultry. 


\section{References}

[1] Pearson, A. M., Dutson, T. R. (2013). Production and processing of healthy meat, poultry and fish products. Springer Science \& Business Media, 367.

[2] Pearson, A. M. (2013). Quality attributes and their measurement in meat, poultry and fish products. Springer, 505.

[3] Zochowska, J., Lachowicz, K., Sobczak, M., Gajowiecki, L. (2007). Effects of Carcass Weight and Muscle on Texture, Structure, Rheological Properties and Myofibre Characteristics of Roe Deer. American Journal of Animal and Veterinary Sciences, 2 (4), 114-120. doi: 10.3844/ajavsp.2007.114.120

[4] García-Segovia, P., Andrés-Bello, A., Martínez-Monzó, J. (2007). Effect of cooking method on mechanical properties, color and structure of beef muscle. Journal of Food Engineering, 80 (3), 813-821. doi: 10.1016/j.jfoodeng.2006.07.010

[5] Damez, J. L., Clerjon, S. (2008). Meat quality assessment using biophysical methods related to meat structure. Meat Science, 80 (1), 132-149. doi: 10.1016/j.meatsci.2008.05.039

[6] Shapoval, S., Forostyana, N., Litvinov, U., Romanenko, R. (2013). Rekomendatsiyi do vikonannya naukovo-doslidnih robit na UVKP. Kyiv: KNTEY, 92.

[7] Datchiki. TOV "Firma ITM". Avaible at: http://itm.com.ua/datchiki/

[8] Panea, B., Ripoll, G., Gonzalez, J., Fernandez-Cuello, A., Albertí, P. (2014). Effect of nanocomposite packaging containing different proportions of $\mathrm{ZnO}$ and $\mathrm{Ag}$ on chicken breast meat quality. Journal of Food Engineering, 123, 104-112. doi: 10.1016/j.jfoodeng.2013.09.029

[9] Romanenko, O. (2013). Metod viznachennya strukturno-mehanichnih vlastivostey ribnih preserviv. Tovari i rinki, 2, 58-65.

[10] Sems, A. (2007). Pererabotka myasa ptitsyi. Saint Petersburg: Professiya, 432.

[11] Savinok, O., Kosoy, V., Garbuz, V. (2015). Vyibor ratsionalnyih parametrov izmereniya reologicheskih harakteristik tselnomyishechnoy tkani govyadinyi metodom penetratsii. Naukovi pratsi ONAHT, 2 (46), 160-163. 